\title{
Circatidal swimming behaviors of fiddler crab Uca pugilator larvae from different tidal regimes
}

\author{
Paola C. López-Duarte*, Richard A. Tankersley \\ Department of Biological Sciences, Florida Institute of Technology, 150 W. University Blvd., Melbourne, Florida 32901, USA
}

\begin{abstract}
Fiddler crab Uca pugilator larvae are released within estuaries near the time of high tide and are exported offshore to undergo development. Previous studies indicate that zoea-1 larvae use selective tidal-stream transport (STST) to migrate from adult habitats to shelf waters. In areas with semidiurnal tides, this behavior is mediated by a circatidal rhythm that is characterized by upward swimming toward the surface during ebb tide, followed by a descent toward the bottom during flood tide. We tested the hypothesis that $U$. pugilator zoeae from different tidal regimes possess activity rhythms that match local tidal patterns. Ovigerous crabs with late-stage embryos were collected from areas with semidiurnal, diurnal, and mixed tides and from an area within a microtidal coastal lagoon. Following hatching, swimming activity was monitored under constant conditions for $96 \mathrm{~h}$. Zoeae from semidiurnal and diurnal regimes possessed activity rhythms with free-running periods that matched the tides at the collection sites ( $\approx 12.4$ and $24.8 \mathrm{~h}$, respectively). Crabs from beaches with mixed tides displayed asymmetrical oscillations in swimming activity with dominant periodicities that corresponded to the semidiurnal and diurnal constituents of the tides. Zoeae from microtidal areas possessed rhythms that were similar to those observed in crabs from areas with semidiurnal tides. At all locations, peaks in activity occurred during the time of expected ebb currents, which is consistent with STST behavior favoring seaward transport. Differences in larval activity patterns suggest that STST behaviors are controlled by separate circatidal and circalunidian clocks or paired circalunidian clocks coupled in antiphase.
\end{abstract}

KEY WORDS: Selective tidal-stream transport · Circatidal · Circalunidian · Endogenous rhythm · Fiddler crab $\cdot$ Uca pugilator $\cdot$ Tidal regimes

Resale or republication not permitted without written consent of the publisher

\section{INTRODUCTION}

Behaviors and physiologies of many estuarine and coastal marine organisms are often synchronized with cyclical changes in water level and horizontal flow associated with the tides (see DeCoursey 1983, Palmer 1995a, Gibson 2003, for reviews). Adaptations for timing activities to predictable changes associated with tidal cycles are most pervasive in marine organisms, such as intertidal and estuarine species, that must cope with short-term environmental fluctuations associated with the tides. Consequently, many organisms possess internal clocks that are used to track the period, phase, and amplitude of the tides and adjust activities and physiologies in anticipation of changes in external conditions (reviewed by DeCoursey 1983, Palmer 1995a).
Circatidal rhythms typically have a period of $12.4 \mathrm{~h}$ (but sometimes $24.8 \mathrm{~h}$; Barnwell 1976) and are entrained or phase-set by environmental cues (zeitgebers) that fluctuate simultaneously with the tidal cycle, including changes in salinity, pressure, temperature, turbulence, vibration, and moonlight (DeCoursey 1983, Naylor \& Williams 1984, Forward 1987, Palmer 1995a, and references therein). Many rhythms are also modulated by the $24 \mathrm{~h}$ day-night cycle, resulting in complex 2 wk (fortnightly) patterns that match the 14.8 d spring-neap cycle (Barnwell 1966).

Although many circatidal rhythms, especially those present in intertidal organisms, are associated with patterns of emersion and submersion tied to changes in water level, others are linked to cycles in the direction of tidal-stream flow. Numerous fish and invertebrate 
species inhabiting estuaries and nearshore coastal areas undergo vertical migrations coupled to tidal flow to take advantage of differences in the horizontal advection of currents associated with tidal phase. This behavior, referred to as selective tidal-stream transport (STST), is often under endogenous control and is used by organisms that are weak swimmers for dispersal and recruitment and by strong swimmers seeking to conserve energy (see Forward \& Tankersley 2001, Gibson 2003 for reviews). Effective unidirectional movement is achieved by vertically migrating upward into the appropriate tidal flow, remaining there for the duration of the tidal phase, and migrating downward and remaining near or on the bottom during the alternate phase (Forward \& Tankersley 2001). Ebb-phased migrations (i.e. ebb-tide transport; ETT) are used for seaward transport and export from estuarine to offshore areas; flood-phased migrations (i.e. flood-tide transport, FTT) are associated with shoreward transport and up-estuary migration for recruitment and settlement in adult habitats (Forward \& Tankersley 2001, Gibson 2003).

Most studies examining vertical migratory behaviors associated with STST have focused on organisms from semidiurnal systems, which predominate the coasts of the Atlantic Ocean, North Sea, and regions of the Indian Ocean (Forward \& Tankersley 2001). These tides are considered the least complex of the tidal forms since they have a period of $\approx 12.4 \mathrm{~h}$ and are characterized by having 2 flood and ebb periods per day of approximately equal magnitude. When broken-down to their principal harmonic components (constituents), tidal changes in these areas are dominated by the principal lunar semidiurnal $\left(\mathrm{M}_{2}=12.42 \mathrm{~h}\right)$ and principal solar semidiurnal partial tides $\left(\mathrm{S}_{2}=12.00 \mathrm{~h}\right)$ (Schureman 1924). However, tidal pattern and form vary geographically depending upon topographical and physical features of the ocean basin and the direction and magnitude of oceanic and tidal currents. Along the coastlines of much of the Pacific and Indian Oceans, the amplitude of successive semidiurnal peaks is altered by a diurnal inequality produced by the moon's declination relative to Earth's equator (Barnwell 1976). Tides in these areas are referred to as being 'mixed' since the complex asymmetrical pattern is determined by the relative influence of the principal semidiurnal constituents $\left(\mathrm{M}_{2}\right.$ and $\left.\mathrm{S}_{2}\right)$ and 2 additional diurnal constituents (lunisolar diurnal $\left[\mathrm{K}_{1}=23.93 \mathrm{~h}\right]$ ) and lunar diurnal $\left(\left[\mathrm{O}_{1}=25.82 \mathrm{~h}\right]\right)$, which are responsible for the inequality between successive peaks (Schureman 1924). Mixed tides are often further subdivided into 2 categories, mainly semidiurnal and mainly diurnal, depending on the relative contribution of the diurnal and semidiurnal partial tides. The relative effect of the diurnal inequality also varies every $13.66 \mathrm{~d}$ as the moon oscillates between the maximum northern and southern limits of its declination cycle (i.e. tropical month $=27.32 \mathrm{~d}$ ). Areas dominated by the $\mathrm{O}_{1}$ and $\mathrm{K}_{1}$ constituents, including parts of the Gulf of Mexico, Southeast Asia, and New Guinea, experience only one high and low tide per day and are classified as diurnal. Finally, some coastal areas, including regions of the Mediterranean, North Sea and the Gulf of Mexico, and estuarine habitats associated with coastal lagoons, lack regular tidal cycles or predictable changes in hydrostatic pressure or current flow. Water level fluctuations in these small-amplitude tidal (microtidal) areas are aperiodic and largely dictated by wind forcing and freshwater run-off (Smith 1987). Little is known about the function and expression of tidally timed activities and behaviors, including those underlying STST, in these systems.

Like many invertebrate and fish species spawned in estuaries, zoeae of the sand fiddler crab Uca pugilator (Bosc) are exported to offshore areas to develop prior to reentering estuaries and recruiting to adult populations as postlarvae (megalopae) (Dittel \& Epifanio 1982, Christy 1982, 2003, Brookins \& Epifanio 1985, Petrone et al. 2005, and references therein). Dispersal to high-salinity areas is considered adaptive since it minimizes exposure to physiologically stressful conditions in estuaries (e.g. low salinity and high temperatures) and reduces the risk of predation (see Morgan 1987, Morgan \& Christy 1997, Christy 2003 for reviews). Transport to offshore areas is facilitated by the synchronous hatching of larvae around the time of high tide (Christy 1982, 1986, Christy \& Stancyk 1982, Morgan 1995, Morgan \& Christy 1995, and references therein) so that larvae are transported down-estuary and away from adult habitats by strong ebb currents. Our recent research indicates that seaward transport is further enhanced through the use of ETT. Newly hatched Stage-1 zoeae from areas with semidiurnal tides possess a circatidal rhythm in swimming activity with a periodicity of approximately $\approx 12.5 \mathrm{~h}$ that persists for several days in the absence of tidally related geophysical or environmental cues (López-Duarte \& Tankersley 2007). Peaks in activity and upward swimming occur $\approx 3 \mathrm{~h}$ after high tide, which corresponds to the expected time of maximum ebb flow. Circatidal migration patterns are consistent with field observations of tidally rhythmic changes in the depth distribution of fiddler crab larvae. Sampling conducted within or near the mouth of estuaries of the western Atlantic has reported tidally synchronized shifts in UCa spp. abundance that were characterized by larvae being concentrated near the surface during the falling tide and in bottom layers when tidal currents were flooding (Brookins \& Epifanio 1985, Epifanio et al. 1988, Garrison 1999). The temporal and spatial (mainly vertical) 
distribution of fiddler crab larvae in areas with mixed and diurnal tides is unknown. Yet, flexibility in the pattern of vertical migration and the timing systems controlling this behavior would be adaptive since it would maximize larval survival and reproductive success across tidal habitats (Barnwell 1976, Thurman 2004). This is especially true in areas where the ability to exploit tidal currents significantly enhances the transport of larvae away from shorelines, where planktivorous fishes are abundant, to coastal waters where environmental conditions are more favorable for development (Morgan 1987, Morgan \& Christy 1997, Christy 2003).

In the present study, the wide geographic distribution of Uca pugilator populations and differences in tidal patterns along the Atlantic and Gulf coasts of Florida (USA) were used to test the hypothesis that the circatidal behaviors of newly hatched zoeae that underlie ETT vary spatially and match the form of the local tidal regime. Estuaries and coastal habitats along the east coast of Florida typically experience semidiurnal tides. However, because of an increase in the dominance of diurnal tidal forcing in the Gulf of Mexico, much of the west coast experiences mixed tides (Coast and Geodetic Survey 1952, NOAA/NOS 2000). The pattern changes again, rather abruptly, near Cape San Blas, Florida (293 $\left.39^{\prime} 55^{\prime \prime} \mathrm{N}, 85^{\circ} 21^{\prime} 00^{\prime \prime} \mathrm{W}\right)$. West of this point and along much of the northern Gulf coast to Vermillion Bay, Louisiana (29³4' 35" N, 92 $02^{\circ}$ '09" W), semidiurnal periodicities are diminished and the tidal form is diurnal (Coast and Geodetic Survey 1952). Zoeae released by adult crabs collected from populations exposed to semidiurnal, diurnal, mixed, and micro-tidal patterns were monitored under constant conditions to determine if they possessed circatidal rhythms in swimming with periods that matched the dominant tidal constituents $\left(\mathrm{M}_{2}\right.$ and $\mathrm{S}_{2} \approx 12.4 \mathrm{~h} ; \mathrm{O}_{1}$ and $\mathrm{K}_{1} \approx 24.8 \mathrm{~h}$ ) associated with the collection site. Vertical migration patterns in the time series were compared to the expected tidal cycle to determine if they were phased appropriately to underlie ETT (i.e. peaks in activity and upward swimming during periods of maximum ebb flow, inactivity and downward swimming during periods of flood flow).

\section{MATERIALS AND METHODS}

Collection of crabs and recording of larval activity. Ovigerous fiddler crabs Uca pugilator (Bosc) were collected during June-August 2003 and September 2005 from 5 sites with different tidal systems located along the Atlantic and Gulf coasts of Florida (USA). Two

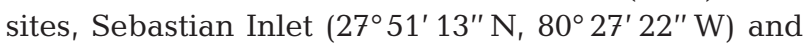
Ft. Pierce Inlet $\left(27^{\circ} 28^{\prime} 27^{\prime \prime} \mathrm{N}, 80^{\circ} 17^{\prime} 49^{\prime \prime} \mathrm{W}\right)$, were on the east coast of Florida (Fig. 1). Tides at both locations are dominated by the principal lunar semidiurnal component $\left(\mathrm{M}_{2}\right)$ and have a period of $\approx 12.4 \mathrm{~h}$ and amplitude of $\approx 0.7 \mathrm{~m}$ (Smith 1987). Crabs experiencing mixed semidiurnal tides were collected from salt marshes adjacent to the Florida State University Coastal and Marine Laboratory (Turkey Point, Florida, USA: $29^{\circ} 54^{\prime} 5^{\prime \prime}$ N, 84 $30^{\prime} 37^{\prime \prime}$ W; Fig. 1). Tides in this area are dominated by both the semidiurnal $\left(\mathrm{M}_{2}\right.$ and $\left.\mathrm{S}_{2}\right)$ and diurnal constituents $\left(\mathrm{K}_{1}\right.$ and $\left.\mathrm{O}_{1}\right)$ with dominant periodicities of $\approx 12.4$ and $\approx 24.8 \mathrm{~h}$ and mean amplitude of $\approx 0.7 \mathrm{~m}$. Tides at the fourth site (Port St. Joe, Florida, USA: $29^{\circ} 48^{\prime} 10^{\prime \prime} \mathrm{N}, 85^{\circ} 18^{\prime} 6^{\prime \prime} \mathrm{W}$ : Fig. 1) are dominated
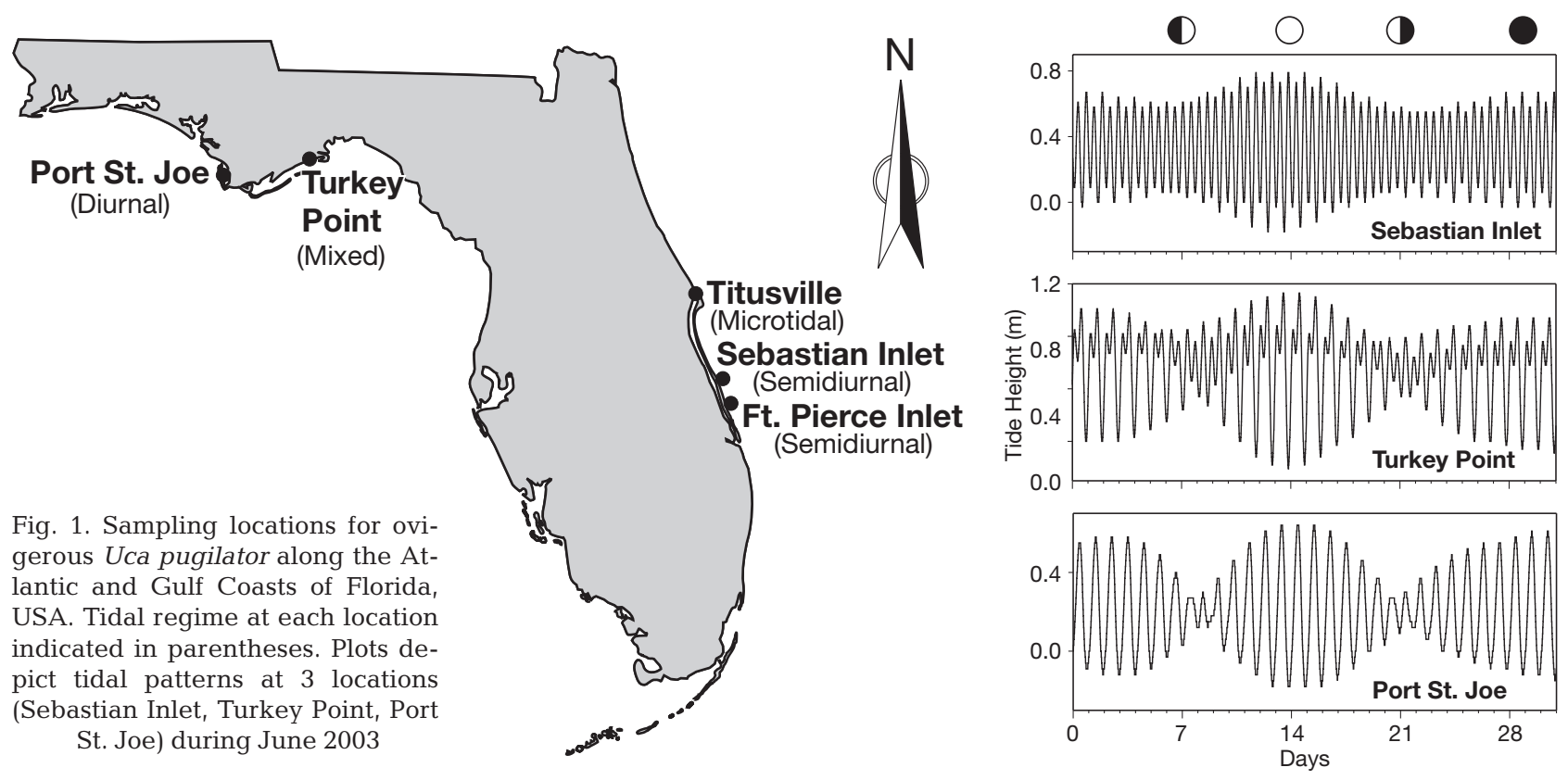
by only the diurnal tidal components $\left(\mathrm{K}_{1}\right.$ and $\left.\mathrm{O}_{1}\right)$, and have a period of $\approx 24.8 \mathrm{~h}$ and an amplitude of $\approx 0.4 \mathrm{~m}$. Crabs from a fifth population were collected from a site on the Atlantic coast of Florida that is within the Indian River Lagoon (Titusville, Florida, USA: $28^{\circ} 37^{\prime} 30^{\prime \prime} \mathrm{N}$, $80^{\circ} 47^{\prime} 32^{\prime \prime} W_{i}$ Fig. 1). Tidally influenced areas in the lagoon are restricted $(<5 \mathrm{~km})$ to regions around the coastal inlets (Smith 1987). The collection site is $>50 \mathrm{~km}$ from the nearest tidal habitat within the lagoon and changes in water level are primarily the result of wind forcing and freshwater runoff (Smith 1987). Thus, the area is classified as being microtidal.

Developmental stage of the embryos in the egg masses was determined using the procedures of Brown \& Loveland (1985). Only crabs that were determined to be within $24 \mathrm{~h}$ of hatching (i.e. late-stage embryos) were used in experiments. In the laboratory, ovigerous crabs were maintained in individual $19 \mathrm{~cm}$ diameter $\times$ $6 \mathrm{~cm}$ glass bowls containing $\approx 1 \mathrm{l}$ of filtered seawater ( 33 to $35 \mathrm{PSU}_{;} 24$ to $25^{\circ} \mathrm{C}$ ) and exposed to a photoperiod that approximated the natural light/dark (L:D) cycle at the time of collection.

Following hatching, zoeae from the same egg mass were transferred to new seawater (34 PSU) and were allowed to feed ad libitum on rotifers (Brachionus sp.) for $1 \mathrm{~h}$. Approximately 200 to 300 larvae were then transferred to clear rectangular Lucite chambers (interior dimensions: $5 \mathrm{~cm} \times 5 \mathrm{~cm} \times 19 \mathrm{~cm}$ ) and placed under constant conditions. Temperature was maintained at $24^{\circ} \mathrm{C}$ and the top of the chamber was partially sealed to prevent evaporation.

Swimming activity of zoeae was recorded continuously for $96 \mathrm{~h}$ under constant far-red illumination (maximum transmission $775 \mathrm{~nm}$ ) using a closed-circuit time-lapse video system (Panasonic BP334 B/W video camera attached to a Panasonic Model RT 650 timelapse video recorder). Recording was considered to be in complete darkness since Uca pugilator larvae are insensitive to far-red light (Cronin \& Forward 1988). The camera's focal length and depth of field were adjusted so that the number and activity of larvae in the upper third of the chamber was recorded. This procedure was repeated 4 times $(\mathrm{N}=4)$ using batches of larvae from different females collected from each of the 4 tidal regimes (semidiurnal, diurnal, mixed semidiurnal and microtidal). Since the Sebastian Inlet and Ft. Pierce Inlet sites are $<45 \mathrm{~km}$ from each other (Fig. 1) and experience similar tidal conditions, 2 replicate groups of larvae from different crabs collected from each site were combined and treated as a single treatment (i.e. semidiurnal tides).

Analysis of activity records. Activity records (actograms) were produced by analyzing the video recordings and counting the number of larvae swimming in the upper third of the chamber at $0.5 \mathrm{~h}$ intervals. Time series of larval activity were analyzed for rhythmicity using Lomb-Scargle periodogram analysis (AutoSignal, SeaSolve Software). The Lomb-Scargle procedure is similar to more traditional Fourier-based spectral methods for analyzing biological time series (e.g. chisquare periodgram), yet it is more appropriate for noisy time series and data sets with unevenly spaced observations (Ruf 1999). Dominant periodic signals in the activity traces were determined by plotting normalized power values (magnitude-squared of the Lomb spectrum) as a function of period (h) (i.e. periodogram). Peak values in the periodogram that exceeded the $95 \%$ confidence interval (calculated using Monte Carlo trials) were considered to be statistically significant at $\alpha=$ 0.05 (Scargle 1982, Chatfield 1989). Confidence intervals are indicated as dashed horizontal lines in the periodogram plots.

If significant rhythmic activity was detected in the time series, the synchrony between larval swimming activity and the expected tidal cycle in the area from which they had been collected was determined using cross-correlation analysis (SPSS 14.0). Predicted tidal heights relative to mean lower low water (MLLW) were obtained from the computer program Tides and Currents Pro 2.5 (Nautical Software) for the Sebastian Inlet, Ft. Pierce Inlet, Turkey Point, and Port St. Joe locations. Since significant tide-related changes in water level do not occur at the Titusville site, tide predictions are unavailable. Thus, tide data for the crosscorrelation analysis was obtained from the nearest $(\approx 30 \mathrm{~km})$ coastal tide station (i.e. Cape Canaveral, Florida, USA). Plots of cross-correlations as a function of lag interval ( $1 \mathrm{lag}=0.5 \mathrm{~h}$ ) were used to determine the phase relationship between swimming behavior and tide stage. Thus, peaks at positive or negative lag intervals indicated that maximum activity occurred that many hours after (+ lags) or before (- lags) the time of expected high tide. Cross-correlation values exceeding the $95 \%$ confidence intervals $( \pm 2 / \sqrt{ } N)$ were considered to be statistically significant (Chatfield 1989).

\section{RESULTS}

Zoea-1 larvae collected from all 5 locations exhibited rhythmic vertical migratory activity under constant conditions. Activity patterns persisted for the duration of the observation period (i.e. $96 \mathrm{~h}$ ) and only dampened slightly, indicating that the rhythms probably continued for several additional cycles beyond the length of the trials (see Figs. 2 to 5). General declines in the overall level of activity were most likely the result of starvation since larvae were not fed once they were placed in constant conditions. In general, zoeae oscil- 
lated between an active phase in which most larvae (75 to $100 \%$ ) swam in the upper portion of the chamber for several hours, followed by an inactive phase in which most larvae remained in the lower portion of the chamber. Dominant periodicities in the time series and the phase relationships between the activity traces and the expected tidal cycle in nature were similar for all trials regardless of the tidal regime, phase of the spring/neap cycle, and synchrony between tidal and diel cycles at the time of release.

Larvae released by crabs collected from Sebastian Inlet (SI) and Ft. Pierce Inlet (FP) exhibited a circatidal rhythm with 2 peaks in activity per day of similar amplitude (Fig. 2). Thus, cycles of activity matched the semidiurnal tidal pattern present at the collection site. Periodograms for all runs contained a single statistically significant $(\mathrm{p}<0.05)$ peak in activity that was comparable to the periodicity of the tides $(\bar{x}: 12.27 \pm$ $0.08 h_{\text {; }}$ Table 1 ; Fig. 2). In all cases, larval activity peaked after high tide during the expected time of ebb tide in the field (Fig. 2). The phase relationship (i.e. acrophase) between the 2 time series was corroborated by significant maximum positive cross-correlation values (maxCC) ranging from 2.5 to $4.5 \mathrm{~h}$ (Table 1 ; $\bar{x}: 3.25 \pm 0.75 \mathrm{~h})$.

Larvae from crabs collected from the same coast of Florida as the SI and FP crabs but in an area within the Indian River Lagoon that does not experience regular tidal changes (Titusville; Fig. 1) also exhibited 2 peaks in swimming activity per day of equal amplitude. This circatidal activity pattern was confirmed by single dominant peaks in the periodograms between 12.19 to $12.49 \mathrm{~h}\left(\bar{x}_{;} ; 12.34 \pm 0.09 \mathrm{~h}\right.$; Fig. 3$)$. Since water level changes at the collection site are aperiodic and not associated with the tides, swimming activity was compared to the expected tidal cycle at an adjacent coastal area (Cape Canaveral, FL) for which tide predictions were available. Although the mean $( \pm \mathrm{SE})$ acrophase for all 4 trials was $3.00 \mathrm{~h}$ $( \pm 1.57 \mathrm{~h})$, the relative synchrony between the 2 time series was more variable than at the other locations and ranged between -0.5 and $7.0 \mathrm{~h}$ relative to high tide (Fig. 3, Table 1).

Activity traces for larvae from gravid females collected at Turkey Point (TP), an area with mixed tides, also exhibited 2 peaks in swimming activity per day. However, the amplitudes of consecutive activity cycles were asymmetrical, indicating that the rhythm was comprised of both circatidal (12.5 h) and circadian $(24 \mathrm{~h})$ or circalunidian $(24.8 \mathrm{~h})$ components. Although the magnitude of the peaks in activity were similar, the troughs (i.e. inactive phases) were unequal, such that more larvae remained near the top of the chamber during inactive periods that occurred during the expected light phase than during the expected dark phase (Fig. 4). This asymmetry matched the mixed-semidiurnal tidal pattern at the collection site during all 4 replicate trials. The circatidal and circadian (or possibly circalunidian) components of the time series were confirmed by the presence of 2 significant $(p<0.05)$ peaks in the periodograms between 12.19 and $12.8 \mathrm{~h}(\bar{x} ; 12.42 \pm$ $0.15 \mathrm{~h})$ and 23.27 to $24.38 \mathrm{~h}\left(\bar{x}_{;} 23.83 \pm 0.32 \mathrm{~h}\right)$, respectively (Fig. 5 ; Table 1 ). When compared to the expected tidal times in the field, maximum swimming activity occurred during the falling tide, $\approx 3.5$ to $5.0 \mathrm{~h}$ after the time of high tide $\bar{x}_{i} 4.13 \pm 0.31 \mathrm{~h}_{i}$ Table 1).

Swimming activity of zoeae spawned by crabs collected at Port St. Joe (SJ) differed substantially from those from the other areas in having only one reoccurring cycle in activity each day, consistent with the diurnal tidal regime present at the collection site. Periodograms for all 4 runs were dominated by a single peak between 24.38 and $25.6 \mathrm{~h}\left(\bar{x}_{;} 24.69 \pm 0.31 \mathrm{~h}\right.$; Table 1), despite the fact that they were from different females. Upward-swimming phases occurred during the expected light phase and were associated with the time of ebb-tide in the field. Mean $( \pm \mathrm{SE})$ acrophase between the activity rhythm and the tide was $6.13 \pm 0.43 \mathrm{~h}$ (Table 1 ), indicating that peaks in activity occurred near the middle of the falling tide (Fig. 5).

Table 1. Uca pugilator. Dominant period lengths $\left(\mathrm{h}_{i} \bar{x}\right)$ for activity rhythms exhibited by groups of zoea-1 larvae from sampling sites with different tidal regimes. Values were obtained using Lomb-Scargle periodogram analysis of $96 \mathrm{~h}$ time series (Figs. 2 to 5). Since 2 significant peaks were present in the periodograms for crabs from the site with mixed tides (Turkey Point), comparable dominant periods were grouped together for analysis and the results reported separately. Acrophase $(\phi)$ values indicate the relative synchrony between the activity traces and their respective expected tidal cycles based on cross-correlation analysis. Reported values are the time lags at which the greatest cross-correlation coefficients between the 2 time series were observed. Thus, lags represent the time of peak activity before (- lags) or after (+ lags) high tide. ( $\mathrm{N}=$ sample size). (FP: Fort Pierce Inlet; SI: Sebastian Inlet; SJ: Port St. Joe; TV: Titusville; TP: Turkey Point)

\begin{tabular}{|c|c|c|c|}
\hline \multirow{2}{*}{ Tidal regime } & Dominant period (h) & Acrophase $(\phi ; \mathrm{h})$ & \multirow[t]{2}{*}{$\mathrm{N}$} \\
\hline & Range & Range & \\
\hline Semidiurnal (SI and FP) & $12.27 \pm 0.08 \quad 12.19-12.49$ & $3.25 \pm 0.75 \quad 2.5-4.5$ & 4 \\
\hline Microtidal (TV) & $12.34 \pm 0.09 \quad 12.19-12.49$ & $3.00 \pm 1.57-0.5-7.0$ & 4 \\
\hline Diurnal (SJ) & $24.69 \pm 0.3124 .38-25.60$ & $6.13 \pm 0.43 \quad 5.0-7.0$ & 4 \\
\hline \multirow[t]{2}{*}{ Mixed semidiurnal (TP) } & $12.42 \pm 0.15 \quad 12.19-12.80$ & $4.13 \pm 0.31 \quad 3.5-5.0$ & 4 \\
\hline & $23.83 \pm 0.3223 .27-24.38$ & & \\
\hline
\end{tabular}


A
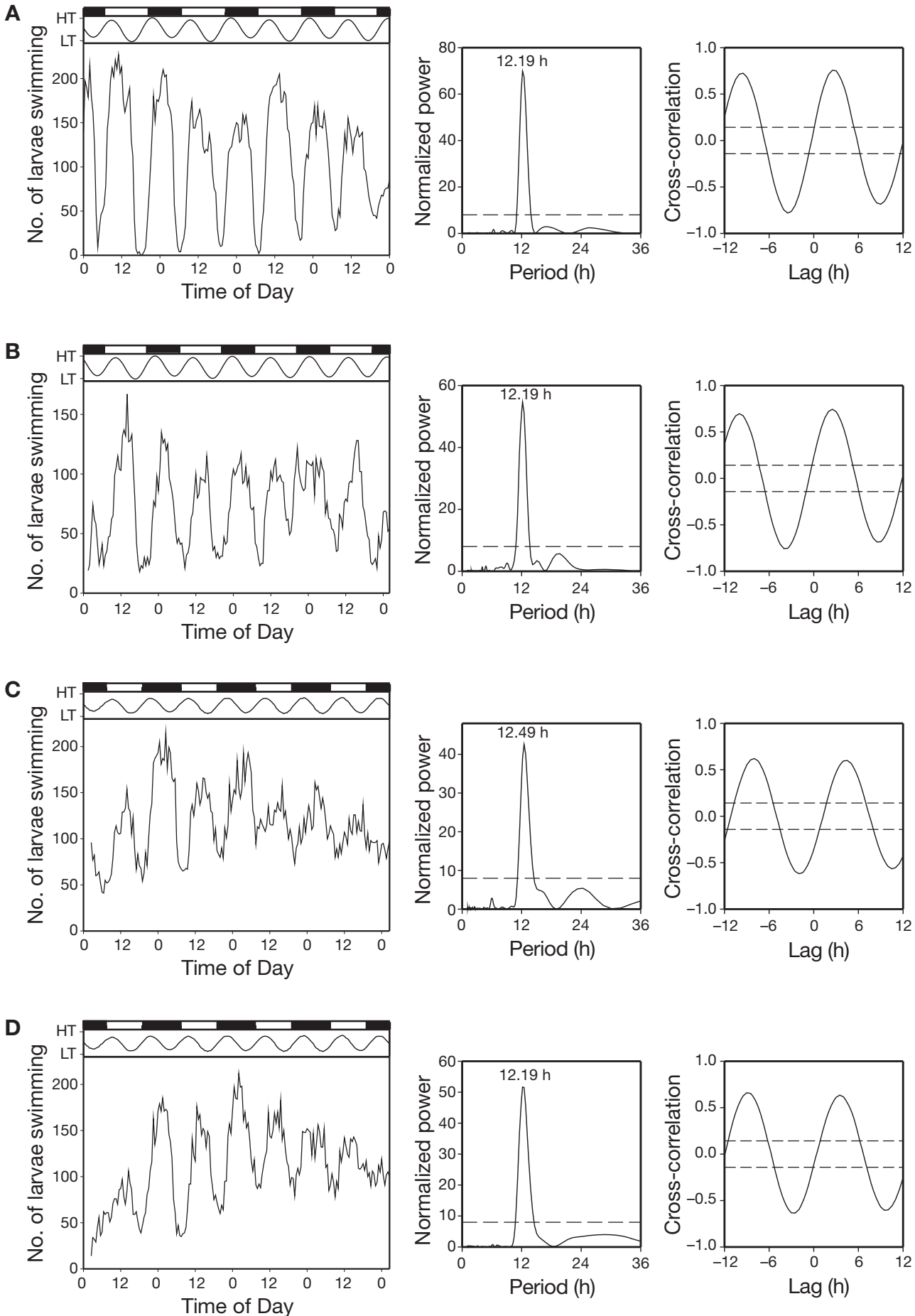

Fig. 2. Uca pugilator. Swimming activity records (actograms; left graphs) and their corresponding periodograms (middle graphs) and cross-correlation plots (right graphs) for newly hatched zoea-1 larvae collected from areas with semidiurnal tides. Plots A and B are for separate (replicate) groups of larvae from Sebastian Inlet, Florida (Fig. 1). Plots C and D are for zoeae from crabs collected from Ft. Pierce, Florida (Fig. 1). Number of zoeae swimming in the upper third of the test chamber is plotted as a function of time. Top abscissas of the actograms include the expected light-dark and tidal (HT, high tide; LT, low tide) cycles in the field. Dashed lines in the periodograms and correlolograms indicate the $95 \%$ confidence intervals. Values above peaks in the periodograms indicate the dominant and statistically significant $(p<0.05)$ periodicity in the time series. Cross-correlation function plots compare the swimming activity to the expected tidal cycles. Lag values compare the synchrony (phase relationship) between swimming activity and tidal height. Thus, significant peaks at positive lags indicate that maximum swimming activity occurred that many hours (lags) after the expected high tide. Peak cross-correlation values at negative lags indicate that maximum swimming occurred prior to high tide 
A
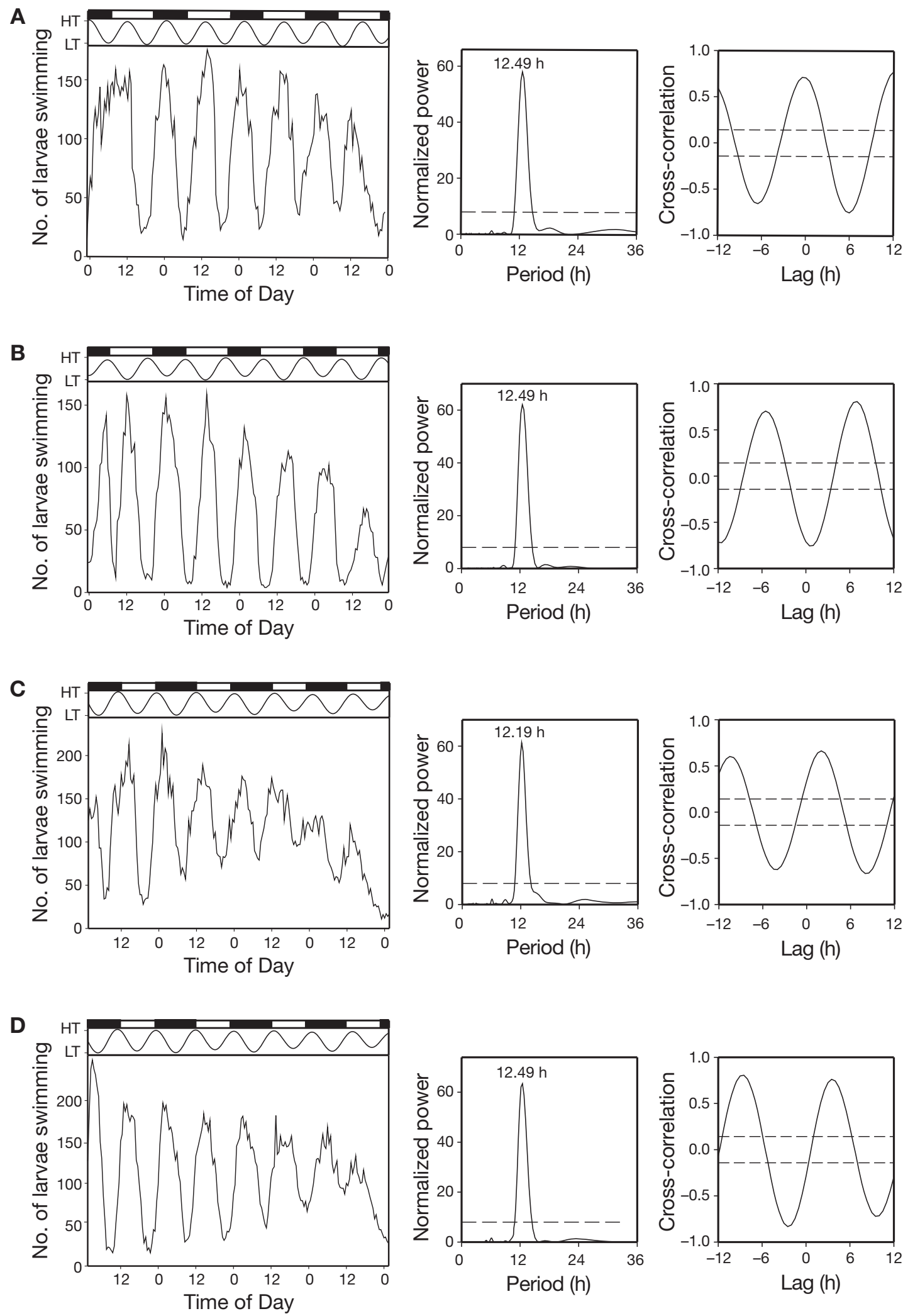

Fig. 3. Uca pugilator. Swimming activity records (actograms; left graphs) and their corresponding periodograms (middle graphs) and cross-correlation plots (right graphs) for newly hatched zoea-1 larvae collected from an area lacking significant tidal changes in water level (microtidal; Titusville, Florida; see Fig. 1). Further details as in the legend for Fig. 2 

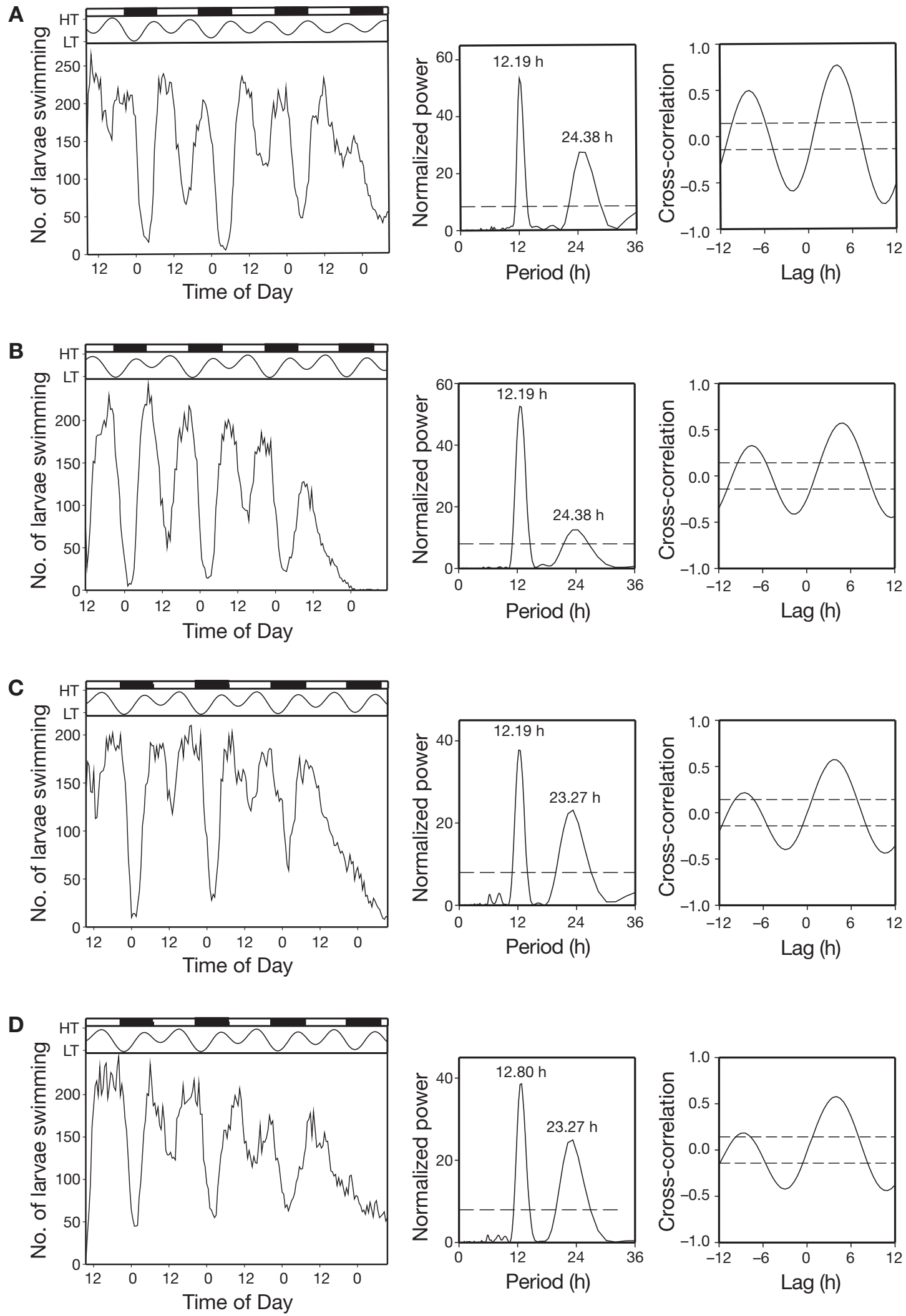

Fig. 4. Uca pugilator. Swimming activity records (actograms; left graphs) and their corresponding periodograms (middle graphs) and cross-correlation plots (right graphs) for newly hatched zoea-1 larvae collected from an area with mixed semidiurnal tides (Turkey Point, Florida; see Fig. 1). Further details as in the legend for Fig. 2 

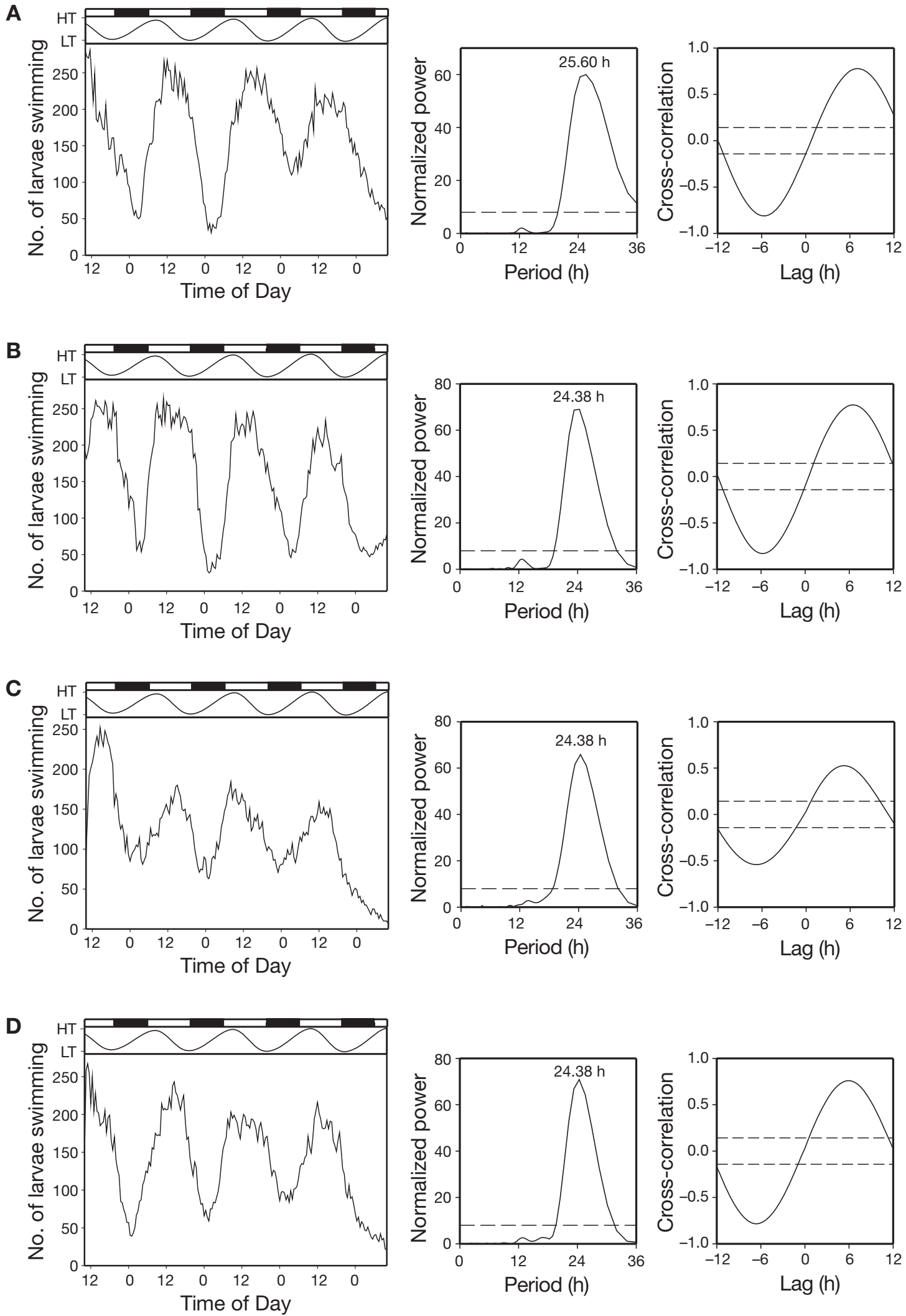

Fig. 5. Uca pugilator. Swimming activity records (actograms; left graphs) and their corresponding periodograms (middle graphs) and cross-correlation plots (right graphs) for newly hatched zoea-1 larvae collected from an area with diurnal tides (Port St. Joe, Florida; see Fig. 1). Further details as in the legend for Fig. 2 


\section{DISCUSSION}

The predominance and nature of tidally related rhythms in marine organisms, especially those inhabiting intertidal areas, has been well documented (for reviews see e.g. DeCoursey 1983, Naylor 1985, Forward 1987, Palmer 1995a). The need for a flexible timing system which enables biological rhythms to adjust to local variations in the phase, period, amplitude, and pattern of the tide was first recognized by Barnwell (1976). However, studies examining the impact of different tidal forms on the expression and utility of circatidal rhythms, especially in species with wide geographic ranges spanning multiple tidal regimes, have largely focused on the locomotory and egg hatching rhythms of adult crabs (see Morgan 1995, Morgan \& Christy 1995, Thurman 2004 for reviews). Nevertheless, how planktonic larvae that are transported considerable distances away from adult habitats cope with spatial variability in the complexity and form of tidal currents is unknown.

Coupling of vertical migration with changes in tidal flow for maintenance of position within estuaries or for directional transport and exchange between estuaries and nearshore coastal areas (i.e. STST) has been well documented in crustaceans (see Forward \& Tankersley 2001, Queiroga \& Blanton 2005, Naylor 2006 for reviews). Available evidence suggests that these movements are primarily controlled by endogenous clocks (Forward \& Tankersley 2001). In addition to UCa pugilator Stage-1 zoeae (López-Duarte \& Tankersley 2007), circatidal rhythms in swimming activity that underlie STST have been reported for larval and adult phases of several other crustaceans, including the copepod Eurytemora affinis (Hough \& Naylor 1992), zoeae of Carcinus maenas (Zeng \& Naylor 1996a,b,c, Duchêne \& Queiroga 2001) and Rhithropanopeus harrisii (Cronin \& Forward 1979, 1983, Forward \& Cronin 1980), postlarvae and juveniles of Penaeus duorarium (Hughes 1972), ovigerous adult blue crabs Callinectes sapidus (Forward et al. 2003), and Uca spp. meglaopae (Tankersley \& Forward 1994). However, previous studies of decapods have focused on species inhabiting locations with semidiurnal tides, and comparisons of STST behaviors among organisms inhabiting areas with different tidal patterns have been limited to populations from tidal and nontidal/microtidal habitats (Zeng \& Naylor 1996a,c, Queiroga et al. 2002). The current study is the first comparison of STST behaviors of a single species across multiple tidal regimes.

Zoeae released by adult Uca pugilator from tidal areas on the Atlantic and Gulf coasts of Florida possessed distinctly different rhythms in swimming activity. Time series for larvae from 2 of the sites along the east coast of Florida (Sebastian Inlet and Ft. Pierce Inlet; Fig. 1) were characterized as having 2 cycles in activity of similar amplitude per lunar day that matched the pattern of the lunar semidiurnal partial tide $\left(\mathrm{M}_{2}\right)$ that dominates this area. These results are comparable to those reported in our earlier study of $U$. pugilator populations inhabiting the Newport River Estuary, North Carolina (López-Duarte \& Tankersley 2007). Crab populations from this location experience tides with properties (period and amplitude) similar to those present at the Sebastian Inlet and Ft. Pierce Inlet sites. As with the present study, Stage-1 zoeae from the Newport river estuary exhibited a tidal rhythm with a mean free running period of $12.59 \pm 0.08 \mathrm{~h}(\bar{x})$ and alternating phases of upward and downward migration were synchronized with the expected times of ebb and flood currents, respectively. Since crab populations for the 2 studies are widely separated $(>800 \mathrm{~km})$, the rhythm is not restricted to a single geographic location or region and is most likely a common behavioral trait of U. pugilator zoeae inhabiting estuaries of east coast of the USA. This conclusion is further supported by field studies conducted in several estuaries along the same coast, including Chesapeake and Delaware Bays, which found abundant newly hatched Uca spp. in surface layers during periods of ebb-flow and in deeper layers during flood (Brookins \& Epifanio 1985, Epifanio et al. 1988, Garrison 1999).

Endogenous rhythms in swimming were also present in zoeae released from crabs from diurnal (SJ) and mixed semidiurnal (TP) tidal regimes. The freerunning periods of rhythms of diurnal crabs were approximately twice as long (24.38 to $25.60 \mathrm{~h}$; Table 1$)$ as those from semidiurnal areas and closely approximated the pattern produced by the $\mathrm{K}_{1}$ and $\mathrm{O}_{1}$ partial tides (Table 1). Thus, a single upward and downward swimming phase occurred each lunar day. Unfortunately, the time series were not sufficiently long enough to determine whether the timing system underlying the rhythm tracks one or both of the geophysical cycles associated with the diurnal harmonic constituents (Stilman \& Barnwell 2004). Similarly, the pattern of the activity rhythm of larvae released by crabs from Turkey Point reflected the relatively complex periodic structure of the mixed semidiurnal tides in the area. Differences in the magnitude of the downward swimming phases of alternating cycles were conspicuous and paralleled the strength of the diurnal inequalities of the tidal regime at the time of hatching. Like larvae from semidiurnal beaches, the timing of the upward swimming phases of the rhythms exhibited by both diurnal and mixed crabs coincided with periods of ebb flow and would promote dispersal away from adult habitats and accelerate seaward transport (Table 1).

Larvae from the microtidal site (Titusville) were predicted to be arrhythmic since both developing embryos 
and gravid females were not exposed to periodic changes in water level or potential entrainment cues associated with tides (e.g. hydrostatic pressure, salinity, turbulence, temperature and immersion/emersion) prior to larval release. Horizontal tidal currents in the area are variable and unpredictable (Smith 1990). Thus, tidally timed vertical migrations would lack ecological and functional significance since they would be energetically costly and of little value for dispersal or transport. Our hypothesis is consistent with previous studies of circatidal behaviors underlying STST. Cronin \& Forward (1983) reported that larval swimming rhythms in the crab Rhithropanopeus harrisii from areas with semidiurnal tides were weaker or absent in laboratory-hatched larvae from crabs collected from areas with aperiodic tides. Similarly, Ehlinger \& Tankersley (2006) found that endogenous swimming behaviors in field-caught larvae of the horseshoe crab Limulus polyphemous were absent in laboratoryreared individuals that were not exposed to artificial tidal cycles in mechanical agitation prior to hatching. Our prediction that larvae would be arrhythmic was not supported since the pattern and periodicity of the swimming rhythms was remarkably similar to the ones recorded for zoeae from the 2 semidiurnal sites (SI and FP; Figs. $2 \& 3$ ) and from a semidiurnal estuary in North Carolina (López-Duarte \& Tankersley 2007). Although the phasing of the active periods relative to the adjacent tidal regime was more variable than for crabs from tidal areas (Table 1), cycles in swimming were well synchronized, as indicated by the sharp peaks in the actograms (Fig. 3).

A possible explanation for the present results comes from similar experiments conducted with first stage zoeae of the shore crab Carcinus maenas. Like Uca pugilator zoeae, C. maenas larvae from areas with semidiurnal tides are released during ebb tides and undergo an ebb-phased migration that results in seaward transport (Zeng \& Naylor 1996a,b, Queiroga et al. 1997). The rhythm underlying the behavior is under endogenous control (Zeng \& Naylor 1996a,b,c, Duchêne \& Queiroga 2001) and appears to be inherited since it is still displayed in laboratory-hatched larvae released by females maintained for several months under constant conditions (Zeng \& Naylor 1996c). Evidence suggests that the hatching process serves to synchronize the circatidal rhythm and associated timing system with falling tides (Zeng \& Naylor 1996a,c). However, Queiroga et al. (2002) found no evidence of a tidal or diel rhythm in vertical migration in laboratory hatched C. maenas zoeae from a microtidal population along the Swedish coast. They hypothesized that Swedish and British Isles C. maenas populations are reproductively isolated and have evolved behavioral adaptations to the local tidal environments.
Given the proximity of the Titusville crabs to other $U$. pugilator populations in the area and the geologic history of the Indian River Lagoon, it is unlikely that they are behaviorally or genetically distinct from nearby populations along the east coast of Florida. Thus, like C. maenas larvae from the British Isles, the swimming rhythm of Titusville crabs may be an inherited circatidal rhythm that is synchronized by the hatching process.

In general, it is unlikely that the circatidal rhythms expressed by Uca pugilator larvae from the Atlantic and Gulf coasts of Florida are the result of genetic differences among populations inhabiting different tidal regimes. Following hatching, fiddler crab larvae are known to be dispersed 10s of $\mathrm{km}$ from the adult habitat (Epifanio et al. 1988, Morgan 2006, Petrone et al. 2005). Consequently, it is generally thought that significant mixing and gene flow occurs among populations, at least those inhabiting the same coastline (Felder \& Staton 1994), and that postlarvae settle and reproduce in areas that may be far from the habitats where they were released. Since tidal regimes may differ over relatively small spatial scales $(<10 \mathrm{~km})$, a flexible timing system would be favored over one that was genetically fixed since a rhythm matching the tides at the natal beach might be unsuitable for tidal patterns at the new settlement/adult habitat (Barnwell 1976, Thurman 2004).

Evidence for flexibility in the timing systems controlling fiddler crab behavioral rhythms comes from studies of geographic variation in the locomotor and larval hatching rhythms of adults. Barnwell (1968) compared the activity rhythms of Uca minax from areas with semidiurnal (Woods Hole, Massachusetts) and diurnal (Ocean Springs, Mississippi) tides. Although the period lengths of the rhythms of the 2 populations differed, crabs transplanted from Massachusetts to Mississippi altered their behavior to match the rhythm of the local population. Temporal patterns of larval release in brachyuran crabs are often synchronized with lunar, semilunar, tidal, and diel cycles and vary with tidal pattern (for reviews see e.g. Forward 1987, Morgan 1995, Morgan \& Christy 1995). Forward et al. (1982) reported different hatching patterns in Rhithropanopeus harrisii collected from tidal and nontidal regions of the same estuary. However, when exposed to artificial tidal cycles in the laboratory, crabs altered their release times to coincide with conditions mimicking high tide. Morgan (1996) reciprocally translocated $U$. pugilator females between 2 of the sites used in the current study-Turkey Point and Port St. Joe. Crabs at both locations have temporally distinct hatching rhythms, yet relocated females adjusted their release patterns to match those of resident crabs within $6 \mathrm{wk}$ of being transferred. Weaver \& Salmon (2002) recently 
reported similar phenotypic plasticity in the hatching rhythms of populations of $U$. thayeri transferred between Florida's east and west coasts. Experiments are currently underway to determine if the rhythmic swimming patterns of $U$. pugilator larvae are genetically fixed traits or phenotypic adaptations to the different tidal regimes.

The distinctiveness and complexity of the rhythms expressed by Uca pugilator zoeae and their similarity to the form and structure of the tides at the study sites provide insights into the timing system controlling circatidal behaviors. Two competing hypothetical models regarding the nature and properties of the underlying oscillator(s) responsible for the patterns exhibited by crabs from different habitats and tidal regimes have been proposed and debated extensively by Naylor (1996, 1997) and Palmer (1995b, 1997, 2000) (Fig. 6). Evidence for both models exists and both can be used to adequately explain the results of the current study. The first is largely based upon studies of the locomotory activity of Carcinus maenas and asserts that endogenous tidal rhythms are controlled by a 'true' circatidal $(\approx 12.4 \mathrm{~h}$ ) oscillator that interacts with other bio- logical oscillators (e.g. circadian and circalunidian) to produce the complex activity rhythms often observed in intertidal crustaceans (Reid \& Naylor 1989, Naylor 1996, 1997, and references therein). Under this scenario, differences in the swimming patterns of $U$. pugilator zoeae are the result of the differential expression of 2 oscillators with fundamentally different periods of $12.4 \mathrm{~h}$ (circatidal) and $24 \mathrm{~h}$ (circadian) or possibly 24.8 h (circalunidian; see Palmer 1995b). In semidiurnal systems, only the underlying circatidal clock is expressed and results in the production of 2 activity cycles of equal amplitude each lunar day (Fig. 6A; left panel). A $12.4 \mathrm{~h}$ oscillator that serves as the dominant or 'default' pacemaker might explain the expression of a strong endogenous $12.4 \mathrm{~h}$ rhythm in larvae from microtidal areas (Fig. 3). In diurnal habitats, the circatidal pacemaker is inhibited or silent and behaviors are primarily controlled by the circadian/circalunidian oscillator. This results in only one activity cycle per lunar day (Fig. 6A; right panel). In mixed systems, activity controlled by the circatidal oscillator is modulated by the second circatidal/circalunidian pacemaker to produce a pattern that includes 2 cycles of

A Dual clock (circatidal and circadian/circalunidian) hypothesis

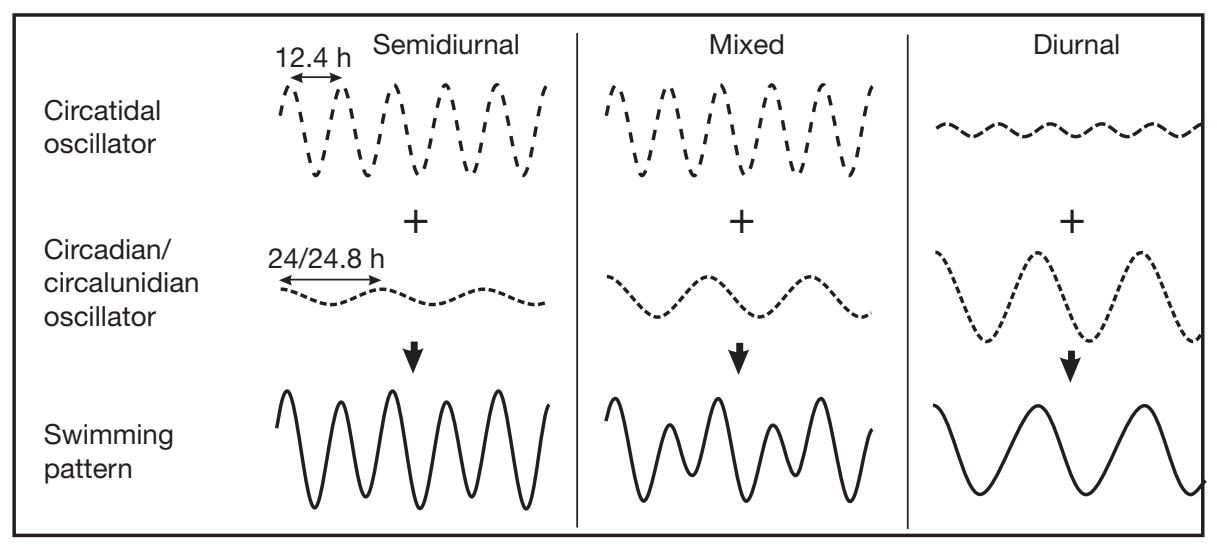

B Coupled circalunidian clock hypothesis

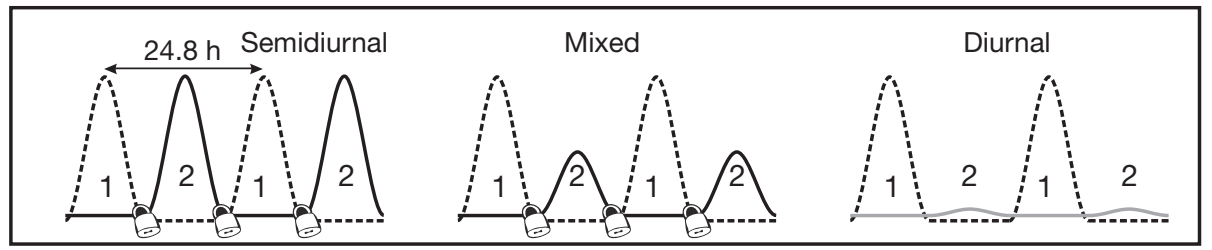

Fig. 6. Diagram of 2 competing hypothetical models proposed to explain the timing systems underlying tidal rhythmic behavior. (A) In the dual-clock hypothesis, rhythmic patterns are the result of the interaction between a 'true' circatidal (12.4 h) pacemaker and a second circadian $(24 \mathrm{~h})$ or circalunidian $(24.8 \mathrm{~h})$ clock (Naylor 1996, 1997). The behavioral pattern is the result of differences in the relative dominance (indicated by the amplitude) of the 2 pacemakers. Alternatively (B), redrawn from Palmer (1995a), the dual circalunidian clock model proposes that circatidal rhythms are the result of the differential expression of 2 independent $24.8 \mathrm{~h}$ lunar day (circalunidian) oscillators (1: dashed line; 2: solid line) that are coupled (designated by lock, 9 ) in antiphase (Palmer 1995a, 2000). Expression of the clocks may be identical, as in semidiurnal systems, or may differ resulting in activity peaks of unequal amplitude (mixed) or the suppression of one of two $24.8 \mathrm{~h}$ cycles each day (diurnal) 
unequal amplitude each lunar day (Fig. 6A; center panel). Thus, the 2 clocks interact in much the same way as the semidiurnal and diurnal tidal constituents combine to produce the complex tidal patterns indicative of mixed regimes.

Proponents of the competing theory assert that endogenous tidal rhythms with periods of $\approx 12.4 \mathrm{~h}$ are actually controlled by 2 circalunidian, not circatidal, oscillators that are coupled $180^{\circ}$ antiphase (Palmer \& Williams 1986, Palmer 1996, 1997). Although the 2 oscillators are 'locked', their properties (i.e. phase and amplitude) can be modified independently and they often become decoupled when animals are placed in constant conditions (Palmer 1995a,b). In semidiurnal systems, the $24.8 \mathrm{~h}$ pacemakers track one of the 2 tidal cycles per lunar day and their expression is nearly identical (Fig. 6A; left panel). However, in diurnal systems, rhythmic behaviors are controlled by only one of the circalunidian oscillators; the other is inhibited or silent (Fig. 6B; right panel). In mixed tidal areas, the 2 clocks are tightly linked, as they are in semidiurnal areas, but they differ in amplitude. Thus, the 2 tidal cycles each day have different properties and result in a complex pattern that is similar to the one exhibited by zoea larvae in mixed-tidal systems (Fig. 4). Thurman (2004) recently argued that a timing system based on 2 circalunidian clocks is more flexible and provides a more economical and practical mechanism for adjusting to changes in tidal patterns than one based on a single circatidal oscillator. Further studies are necessary to determine which of these models of the clocks underlying endogenous tidal rhythms best explains the STST behaviors of UCa pugilator larvae, and to investigate the cue(s) responsible for entrainment and synchronization of the clocks in different tidal systems.

Acknowledgements. The study was completed by P.L-D. in partial fulfillment of the requirements of the Doctorate of Philosophy degree from the Florida Institute of Technology. Funding was provided by the National Science Foundation (OCE 9901146/0096205 and OCE 0094930). We are grateful to P. Gravinese, P. Pochelon, and N. Saran for their help with the collection and maintenance of crabs. The staff of the Florida State Coastal and Marine Laboratory graciously provided space and logistical support.

\section{LITERATURE CITED}

Barnwell FH (1966) Daily and tidal patterns of activity in individual fiddler crab (Genus Uca) from the Woods Hole region. Biol Bull (Woods Hole) 130:1-17

Barnwell FH (1968) The role of rhythmic systems in the adaptation of fiddler crabs to the intertidal zone. Am Zool 8: 569-583

Barnwell FH (1976) Variation in the form of the tide and some problems it poses for biological timing systems. In: De
Coursey PJ (ed) Biological rhythms in the marine environment. University of South Carolina Press, Columbia, SC, p 161-187

Brookins KG, Epifanio CE (1985) Abundance of brachyuran larvae in a small coastal inlet oversix consecutive tidal cycles. Estuaries 8:60-67

Brown SK, Loveland RE (1985) A calibration method to generate seasonal hatching profiles for the fiddler crabs Uca pugnax (Smith, 1887) and Uca minax (LeConte, 1855) (Decapoda: Brachyura). J Exp Mar Biol Ecol 90:27-42

Chatfield C (1989) The analysis of time series: an introduction. Chapman \& Hall, New York

Christy JH (1982) Adaptive significance of semilunar cycles of larval release in fiddler crabs (Genus $U_{c a}$ ): test of an hypothesis. Biol Bull (Woods Hole) 163:251-263

Christy JH (1986) Timing of larval release by intertidal crabs on an exposed shore. Bull Mar Sci 39:176-191

Christy JH (2003) Reproductive timing and larval dispersal of intertidal crabs: the predator avoidance hypothesis. Rev Chil Hist Nat 76:177-185

Christy JH, Stancyk SE (1982) Timing of larval production and flux of invertebrate larvae in a well-mixed estuary. In: Kennedy VS (ed) Estuarine comparisons. Academic Press, New York, p 489-503

Coast and Geodetic Survey (1952) Manual of harmonic constant reductions. Special Publication 260, US Department of Commerce, US Government Printing Office, Washington, DC

Cronin TW, Forward RB Jr (1979) Tidal vertical migration: an endogenous rhythm in estuarine crab larvae. Science 205:1020-1022

Cronin TW, Forward RB Jr (1983) Vertical migration rhythms of newly-hatched larvae of the estuarine crab, Rhithropanopeus harrisii. Biol Bull (Woods Hole) 165:139-153

Cronin TW, Forward Jr RB (1988) The visual pigments of crabs. I. Spectral characteristics. J Comp Physiol 162: 463-478

DeCoursey PJ (1983) Biological timing. In: Bliss DE Mantele LH (eds) The biology of Crustacea, Vol. 7. Academic Press, New York, p 107-162

Dittel AI, Epifanio CE (1982) Seasonal abundance and vertical distribution of crab larvae in Delaware Bay, USA. Estuaries 5:197-202

Duchêne JC, Queiroga H (2001) Use of intelligent CCD camera for the study of endogenous vertical migration rhythms in first zoeae of the crab Carcinus maenas. Mar Biol 139:901-909

Ehlinger GS, Tankersley RA (2006) Endogenous rhythms and entrainment cues of larval activity in horseshoe crab Limulus polyphemus. J Exp Mar Biol Ecol 337: 205-214

Epifanio CE, Little KT, Rowe PM (1988) Dispersal and recruitment of fiddler crab lavae in the Delaware River estuary. Mar Ecol Prog Ser 43:181-188

Felder DL, Staton JL (1994) Genetic differentiation in transFloridan species complexes of Sesarma and UCa (Decapoda: Brachyura). J Crustac Biol 14:191-209

Forward RB Jr (1987) Larval release rhythms of decapod crustaceans: an overview. Bull Mar Sci 41:165-176

Forward RB Jr, Cronin TW (1980) Tidal rhythms in activity and phototaxis by an estuarine crab larva. Biol Bull (Woods Hole) 158:295-303

Forward RB Jr, Tankersley RA (2001) Selective tidal-stream transport of marine animals. Oceanogr Mar Biol Annu Rev 39:305-353

Forward RB Jr, Lohmann K, Cronin TW (1982) Rhythms in larval release by an estuarine crab (Rhithropanopeus harrisii). Biol Bull (Woods Hole) 163:287-300 
Forward RB Jr, Tankersley RA, Pochelon PN (2003) Circatidal activity rhythms in ovigerous blue crabs, Callinectes sapidus: implications for ebb-tide transport during the spawning migration. Mar Biol 142:67-76

Garrison LP (1999) Vertical migration behavior and larval transport in brachyuran crabs. Mar Ecol Prog Ser 176:103-113

Gibson RN (2003) Go with the flow: tidal migration in marine animals. Hydrobiologia 503:153-161

Hough AR, Naylor E (1992) Endogenous rhythms of circatidal swimming activity in estuarine copepod Eurytemora affinis (Poppe). J Exp Mar Biol Ecol 161:27-32

Hughes DA (1972) On the endogenous control of tideassociated displacements of pink shrimp, Penaeus duorarum Burkenroad. Biol Bull (Woods Hole) 142:271-280

López-Duarte PC, Tankersley RA (2007) Circatidal swimming behavior of brachyuran crab zoea larvae: implications for ebb-tide transport. Mar Biol 151:2037-2051

Morgan SG (1987) Adaptive significance of hatching rhythms and dispersal patterns of estuarine crab larvae: avoidance of physiological stress by larval export? J Exp Mar Biol Ecol 113:71-78

Morgan SG (1995) The timing of larval release. In: McEdward LR (ed) The ecology of marine invertebrate larvae. CRC Press, Boca Raton, FL, p 157-191

Morgan SG (1996) Plasticity in reproductive timing by crabs in adjacent tidal regimes. Mar Ecol Prog Ser 139:105-118

Morgan SG (2006) Larval migration between the Hudson River estuary and New York Bight. In: Levinton JS, Waldman JR (eds) The Hudson River Estuary. Cambridge University Press, New York, p 157-170

Morgan SG, Christy JH (1995) Adaptive significance of the timing of larval release by crabs. Am Nat 145:457-479

Morgan SG, Christy JH (1997) Planktivorous fishes as selective agents for the timing of larval release. J Exp Mar Biol Ecol 209:89-101

NOAA/NOS (2000): Tidal datums and their applications. NOAA Special Publication NOS CO-OPS 1, Silver Springs, MD

Naylor E (1985) Tidally rhythmic behaviour of marine animals. Symp Soc Exp Biol 39:63-93

Naylor E (1996) Crab clockwork: the case for interactive circatidal and circadian oscillators controlling rhythmic locomotor activity of Carcinus maenas. Chronobiol Int 13: 153-161

Naylor E (1997) Crab clocks rewound. Chronobiol Int 14: $427-430$

Naylor E (2006) Orientation and navigation in coastal and estuarine zooplankton. Mar Freshw Behav Physiol 39: $13-24$

Naylor E, Williams BG (1984) Phase-responsiveness of the circatidal locomotor activity rhythm of Hemigrapsus edwardsi (Hilgendorf) to simulated high tide. J Mar Biol Assoc UK 64:81-90

Palmer JD (1995a) The biological rhythms and clocks of intertidal animals. Oxford University Press, New York

Palmer JD (1995b) A review of the dual-clock control of tidal rhythms and the hypothesis that the same clock governs both circatidal and circadian rhythms. Chronbiol Int 12 : 299-310

Palmer JD (1996) Time, tide and the living clocks of marine organisms. Am Sci 84:570-578

Palmer JD (1997) Dueling hypotheses: circatidal versus cir- calunidian battle basics. Chronobiol Int 14:337-346

Palmer JD (2000) The clocks controlling the tide-associated rhythms of intertidal animals. Bioessays 22:32-37

Palmer JD, Williams BG (1986) Comparative studies of tidal rhythms. II. The dual clock control of the locomotor rhythms of two decapod crustaceans. Mar Behav Physiol 12:269-278

Petrone C, Jancaitis LB, Jones MB, Natunewicz CC, Tilburg CE, Epifanio CE (2005) Dynamics of larval patches: spatial distribution of fiddler crab larvae in Delaware Bay and adjacent waters. Mar Ecol Prog Ser 293:177-190

Queiroga H, Blanton J (2005) Interactions between behaviour and physical forcing in control of horizontal transport of decapod crustacean larvae. Adv Mar Biol 47:107-214

Queiroga HJ, Costlow JD, Moreira MH (1997) Vertical migration of the crab Carcinus maenus first zoeae in an estuary: implications for tidal stream transport. Mar Ecol Prog Ser 149:121-132

Queiroga H, Moksnes PO, Meireles S (2002) Vertical migration behaviour in the larvae of the shore crab Carcinus maenas from a microtidal system (Gullmarsfjord, Sweden). Mar Ecol Prog Ser 237:195-207

Reid DG, Naylor E (1989) Are there separate circatidal and circadian clocks in the shore crab Carcinus maenas? Mar Ecol Prog Ser 52:1-6

Ruf $\mathrm{T}$ (1999) The Lomb-Scargle periodogram in biological rhythm research: analysis of incomplete and unequally spaced time-series. Biol Rhythm Res 30:178-201

Scargle JD (1982) Studies in astronomical time series analysis. II. Statistical aspects of spectral analysis of unevenly spaced data. Astrophys J 263:835-853

Schureman P (1924) Tides: A manual of the harmonic analysis and prediction of tides. Special Publication 98, US Coast and Geodetic Survey, Washington, DC

Smith NP (1987) An introduction to the tides of Florida's Indian River Lagoon. I. Water levels. Fla Sci 50:4961

Smith NP (1990) An introduction to the tides of Florida's Indian River Lagoon. II. Currents. Fla Sci 53:216-225

Stillman JH, Barnwell FH (2004) Relationship of daily and circatidal activity rhythms of the fiddler crab, Uca princeps, to the harmonic structure of semidiurnal and mixed tides. Mar Biol 144:473-482

Tankersley RA, Forward Jr RB (1994) Endogenous activity rhythms in two estuarine crab megalopae: implications for flood tide transport. Mar Biol 118:415-424

Thurman CL (2004) Unravelling the ecological significance of endogenous rhythms in intertidal crabs. Biol Rhythm Res 35:43-67

Weaver A, Salmon M (2002) Hatching rhythms of Uca thayeri: evidence for phenotypic plasticity. J Crustac Biol 22: $429-438$

Zeng C, Naylor E (1996a) Synchronization of endogenous tidal vertical migration rhythms in laboratory-hatched larvae of the crab Carcinus maenas. J Exp Mar Biol Ecol 198:269-289

Zeng C, Naylor E (1996b) Endogenous tidal rhythms of vertical migration in field collected zoea-1 larvae of the shore crab Carcinus maenas: implications for ebb-tide offshore dispersal. Mar Ecol Prog Ser 132:71-82

Zeng C, Naylor E (1996c) Heritability of circatidal vertical migration rhythms in zoea larvae of the crab Carcinus maenas (L.). J Exp Mar Biol Ecol 202:239-257

Submitted: December 19, 2006; Accepted: February 8, 2007 Proofs received from author(s): July 18, 2007
Editorial responsibility: Otto Kinne (Editor-in-Chief), Oldendorf/Luhe, Germany 